\title{
Design and Development of a Group Decision Support System for the Evaluation and Selection of Research Projects
}

\author{
Irakli Basheleishvili \\ Department of Computer Technology \\ Akaki Tsereteli State University \\ Kutaisi, Georgia \\ irakli.basheleishvili@atsu.edu.ge
}

\author{
Avtandil Bardavelidze \\ Department of Computer Technology \\ Akaki Tsereteli State University \\ Kutaisi, Georgia \\ avtandil.bardavelidze@atsu.edu.ge
}

\begin{abstract}
The current paper deals with the design and development of a web-based group decision support system for the evaluation and selection of research projects. The paper involves the analysis of the system's requirements, the definition of its functional structure, the development of an algorithm for the evaluation and ranking of research projects, the development of a related database and of a user interface along with the writing of the business logic of the system.
\end{abstract}

Keywords-research projects; group decision; evaluation; selection; multi-criteria analysis

\section{INTRODUCTION}

Decision-making is one of the most difficult problems of human activity, whose solution depends on the effective implementation of relevant activities. Decision-making problems are analytical problems that allow, relying on the primary information base, gaining new knowledge concerning the new situation, deeply understanding the current processes and, consequently, making the right decision [1]. In order to solve such problems, it is important to use the information systems called decision support systems [1-4] which are the model-based or knowledge-based systems designed to assist in decision-making [2].

The current paper deals with the design and development of a group decision support system for the evaluation and ranking of research projects. In decision-making theory and practice, great importance is attached to the so-called group decisions made by several individuals. There is particular interest in group decisions due to the fact that there is a high level of professionalism in society, and at the same time, the physical and informational capacities of an individual are quite limited. The use of this type of system is mainly needed by organizations that announce research grant competitions. The grant competition process can generally be described as follows: the granting organizations announce a scientific grant competition in various fields of science and define the requirements for the research projects. After the announcement of the grant competition, the applicants submit their project proposals according to the area of research, after which the granting organization appoints a group of experts for the relevant projects, and the experts review and evaluate the submitted project proposals. The granting organization makes the decision to select the best research projects based on the experts' evaluation.

Today there are numerous management information systems used by the organizations providing research grants [8]. The functionality of these systems is largely limited to allowing the grant applicants meet the requirements of a grant project in accordance with the requirements of the organization providing these grants, that is, they are mostly engaged in data collection and submission. These systems do not support decision-making on grant selection. The proposed system, in addition to all these, has the novelty of decision-making support which increases its practical value, making the activities of the grant-proving organizations more effective.

The aim of the current paper is the design and development of a web-based group decision support system that provides support for the research grant competition processes with a view to conduct the research grant competition in an efficient and fair manner. A web-based group decision support system will allow the involvement in this competition of applicants from various and distant geographical locations.

\section{IDENTIFYING THE SYSTEM’S REQUIREMENTS}

A use case diagram (Figure 1) was developed to specify and analyze the requirements of the group decision support system for the evaluation and selection of research projects. The diagram illustrates the requirements and the functionality that will be imposed on the design system. As shown in this use case diagram, there are four types of roles in the system:

- Administrator: manages the users of the other levels of the system and ensures the efficient operation of the system.

- Manager: represents the organization that announces the research grant competition. The user having this this role:

o Defines the areas of the research grant competition. 


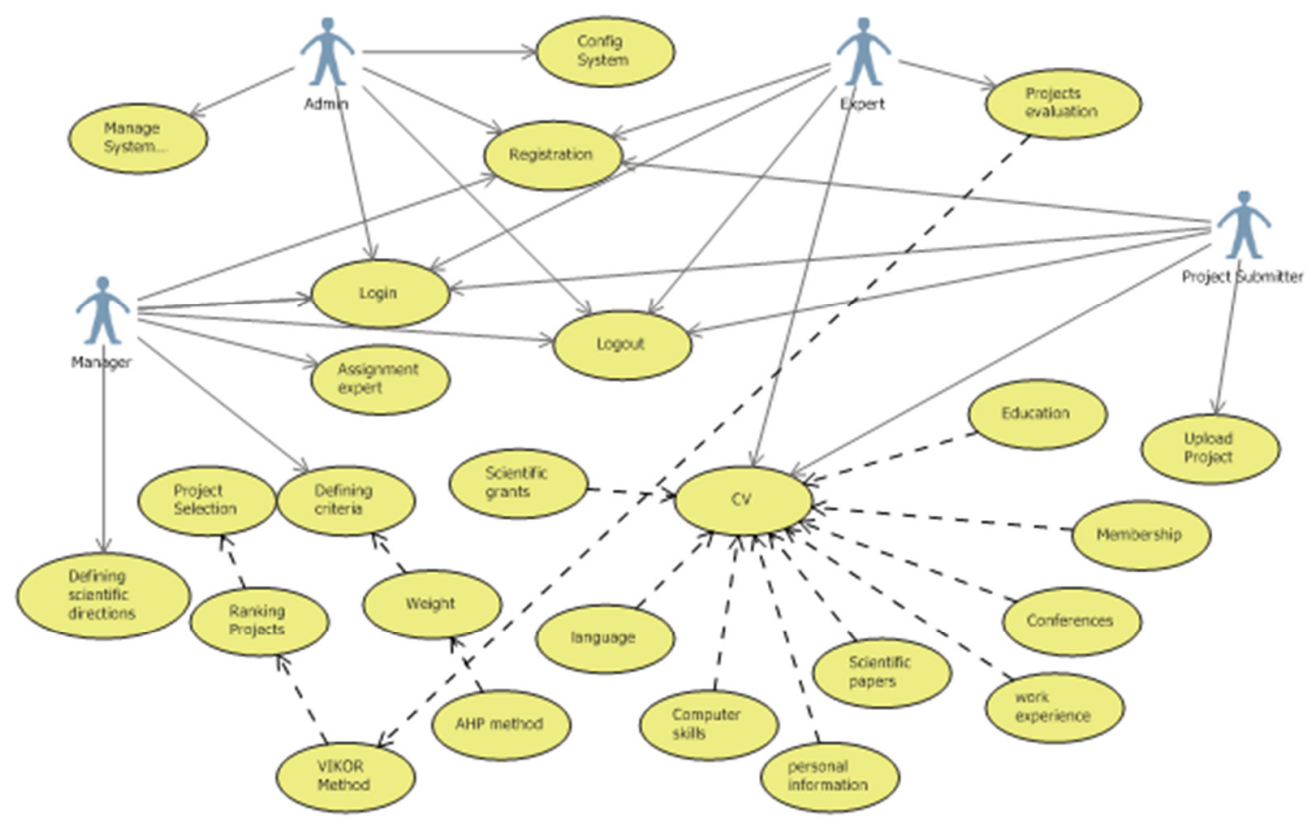

Fig. 1. Use case diagram.

- Identifies the requirements and necessary documents for the submission of the research project.

- Defines the evaluation criteria and their weights in accordance with the areas of the research grant competition.

- Nominates the experts in accordance with the scientific areas of the submitted research projects.

○ Ranks the research projects based on the experts' evaluation.

- Makes the decision of selecting the research projects.

- Submitter of the research project: this user is registered in the system and submits the information and documentation required for the submission of the grant research project. The submitter of the research project in the system can get information about the evaluation of his research project and the decision on selecting the project, after the evaluation of the project by experts.

- Experts: are registered users in the system and their main function is to evaluate research projects in accordance with the previously defined evaluation criteria, for the projects of the scientific fields that they were nominated for by the manager.

The users of the system can use the above mentioned functions if they are authorized by the system. To do this, it is necessary for them to register and get a confirmation from the administrator.

\section{DEVELOPMENT OF THE REQUIRED ALGORITHM FOR THE OPERATION OF THE SYSTEM}

The main issue when designing decision support systems is the development of the mathematical models and the algorithms necessary for its operation. The decision-making problems, in which the possible alternatives are evaluated according to several criteria, are of particular interest. In this case we are dealing with multi-criteria decision-making problems [10]. The problem of evaluating and ranking research projects is a multi-criteria problem, in which the research projects are considered to be the alternatives, while the research project evaluation criteria are considered to be the alternative evaluation criteria. Therefore, multi-criteria decision analysis methods are used to develop an algorithm for evaluating and ranking research projects [3]. Many theoretical studies have been dedicated to this problem, but the analysis reveals that their application in practice is not always possible and is time consuming. Therefore, it is relevant to develop user-friendly, multi-criteria decision-making algorithms and the appropriate software system for practical use, which will allow the decision-makers to promptly evaluate the multi-criteria alternatives and make optimal decisions.

\section{A. The Ranking Algorithm}

The ranking of the research projects is carried out once the group of experts evaluates the research projects according to the relevant criteria, based on which it will be possible to form a decision matrix: 


$\begin{array}{cccccc} & C_{1} & C_{2} & C_{3} & \cdots & C_{m} \\ A_{1} & x_{11} & x_{12} & x_{13} & \cdots & x_{1 m} \\ A_{2} & x_{21} & x_{22} & x_{23} & \cdots & x_{2 m} \\ A_{3} & x_{31} & x_{32} & x_{33} & \cdots & x_{3 m} \\ \vdots & \vdots & \vdots & \vdots & \ddots & \vdots \\ A_{n} & x_{n 1} & x_{n 2} & x_{n 3} & \cdots & x_{n m} \\ & w_{1} & w_{2} & w_{3} & \cdots & w_{m}\end{array}$

where $x_{i j}, i=1, \ldots, n, j=1, \ldots ., m$ represent the assessment of the $i$ alternative in accordance with the $j$ criterion, defined by the experts. The value of $x_{i j}$ is calculated as:

$$
x_{i j}=\frac{1}{t}\left(x_{i j}^{1}+x_{i j}^{2}+x_{i j}^{3}+\cdots+x_{i j}^{t}\right)
$$

where $x_{i j}^{k}, k=1, t$ is the $\mathrm{k}^{\text {th }}$ - expert's assessment of the $j$ criterion of the $i$ alternative.

The multi-criteria decision analysis method AHP is used to calculate the weights of the alternative evaluation criteria $[2,5$ 8]. The Vikor method [9] was used to identify the research projects. It includes the following steps:

Step 1: Determine the best $x_{j}^{+}$and the worst $x_{j}^{-}$values of all criteria:

$$
\begin{aligned}
& x_{j}^{+}=\max \left(x_{i j}\right), j=1, \ldots, m \\
& x_{j}^{-}=\min \left(x_{i j}\right), j=1, \ldots, m
\end{aligned}
$$

Step 2: Calculate $S_{i}$ and $R_{i}$ using (4) and (5):

$$
\begin{gathered}
s_{i}=\sum_{j=1}^{m}\left(w_{j} * \frac{x_{j}^{+}-x_{i j}}{x_{j}^{+}-x_{j}^{-}}\right) \\
R_{i}=\max _{j}\left(w_{j} * \frac{x_{j}^{+}-x_{i j}}{x_{j}^{+}-x_{j}^{-}}\right)
\end{gathered}
$$

Step 3: Compute the values $Q_{i}$ using (6):

$$
Q_{i}=v^{*} \frac{S_{i}-S^{+}}{S^{-}-S^{+}}+(1-v) * \frac{R_{i}-R^{+}}{R^{-}-R^{+}}
$$

where $S^{+}=\min _{i} S_{i}, S^{-}=\max _{i} S_{i}, R^{+}=\min _{i} R_{i}, R^{-}=\max _{i} R_{i}$, and $v=0.5$

Step 4: Ranking of the alternatives for the $Q_{i}$ values: The rank of alternatives is determined by sorting the obtained values from small to large.

\section{B. Numerical Experiment}

To demonstrate the work of the presented algorithm, lets consider a practical case, Let's assume we want to evaluate five projects $\left(A_{1}, . ., A_{5}\right)$ that are evaluated according to four criteria $\left(c_{1}, . ., c_{4}\right)$. Let's assume that the decision matrix based on the experts' evaluations has the form exhibited in Table I.
TABLE I. DECISION MATRIX

\begin{tabular}{|l|l|l|l|l|}
\hline & $\boldsymbol{c}_{\mathbf{1}}$ & $\boldsymbol{c}_{\boldsymbol{2}}$ & $\boldsymbol{c}_{\mathbf{3}}$ & $\boldsymbol{c}_{\mathbf{4}}$ \\
\hline $\boldsymbol{A}_{\mathbf{1}}$ & 90 & 70 & 85 & 79 \\
\hline $\boldsymbol{A}_{\mathbf{2}}$ & 87 & 75 & 96 & 89 \\
\hline $\boldsymbol{A}_{\mathbf{3}}$ & 80 & 79 & 74 & 75 \\
\hline $\boldsymbol{A}_{\mathbf{4}}$ & 75 & 80 & 92 & 78 \\
\hline $\boldsymbol{A}_{\mathbf{5}}$ & 82 & 75 & 69 & 96 \\
\hline
\end{tabular}

The pairwise comparison matrix of the criteria of assessment is shown in Table II and the normalized pair-wise comparison matrix in Table III. The vector of the weights is determined as:

$$
c_{1}=0.48 \quad c_{2}=0.29 \quad c_{3}=0.13 \quad c_{4}=0.09
$$

The calculated weighted normalized decision matrix is shown in Table IV. The calculated sum of the weighted values is:

$$
\mathrm{c}_{1}=1.97 \quad \mathrm{c}_{2}=1.21 \quad \mathrm{c}_{3}=0.54 \quad \mathrm{c}_{4}=0.38
$$

The calculated $\lambda_{\max }$ is 4.077618 . The calculated Consistency Index (CI) is 0.025873 and the Consistency Ratio (CR) is 0.028748 . Because the CR value is less than 0.1 it is acceptable. The determined best $x_{j}^{+}$and the worst $x_{j}^{-}$values of all criteria are shown in Table V. Then, $S_{i}, R_{i}$, and $Q_{i}$ are calculated. The final result is shown in Table VI.

TABLE II. PAIRWISE COMPARISON MATRIX

\begin{tabular}{|c|c|c|c|c|}
\hline & $\boldsymbol{c}_{\mathbf{1}}$ & $\boldsymbol{c}_{\mathbf{2}}$ & $\boldsymbol{c}_{\mathbf{3}}$ & $\boldsymbol{c}_{\mathbf{4}}$ \\
\hline$c_{1}$ & 1.00 & 2.00 & 4.00 & 4.00 \\
\hline$c_{2}$ & 0.50 & 1.00 & 3.00 & 3.00 \\
\hline$c_{3}$ & 0.25 & 0.33 & 1.00 & 2.00 \\
\hline$c_{4}$ & 0.25 & 0.33 & 0.50 & 1.00 \\
\hline
\end{tabular}

TABLE III. NORMALIZED PAIRWISE COMPARISON MATRIX

\begin{tabular}{|c|c|c|c|c|}
\hline & $\boldsymbol{c}_{\mathbf{1}}$ & $\boldsymbol{c}_{\mathbf{2}}$ & $\boldsymbol{c}_{\mathbf{3}}$ & $\boldsymbol{c}_{\mathbf{4}}$ \\
\hline$c_{1}$ & 0.50 & 0.55 & 0.47 & 0.40 \\
\hline$c_{2}$ & 0.25 & 0.27 & 0.35 & 0.30 \\
\hline$c_{3}$ & 0.13 & 0.09 & 0.12 & 0.20 \\
\hline$c_{4}$ & 0.13 & 0.09 & 0.06 & 0.10 \\
\hline
\end{tabular}

TABLE IV. WEIGHTED NORMALIZED MATRIX

\begin{tabular}{|l|c|c|c|c|}
\hline & $\boldsymbol{c}_{\boldsymbol{1}}$ & $\boldsymbol{c}_{\mathbf{2}}$ & $\boldsymbol{c}_{\mathbf{3}}$ & $\boldsymbol{c}_{\boldsymbol{4}}$ \\
\hline $\boldsymbol{c}_{\boldsymbol{1}}$ & 0.48 & 0.59 & 0.53 & 0.37 \\
\hline $\boldsymbol{c}_{\boldsymbol{2}}$ & 0.24 & 0.29 & 0.40 & 0.28 \\
\hline $\boldsymbol{c}_{\boldsymbol{3}}$ & 0.12 & 0.10 & 0.13 & 0.19 \\
\hline $\boldsymbol{c}_{\boldsymbol{4}}$ & 0.12 & 0.10 & 0.07 & 0.09 \\
\hline
\end{tabular}

TABLE V. BEST AND WORST VALUES OF ALL CRITERIA

\begin{tabular}{|l|l|l|l|l|}
\hline & $\boldsymbol{c}_{\boldsymbol{1}}$ & $\boldsymbol{c}_{\boldsymbol{2}}$ & $\boldsymbol{c}_{\mathbf{3}}$ & $\boldsymbol{c}_{\mathbf{4}}$ \\
\hline $\boldsymbol{x}_{\boldsymbol{j}}^{+}$ & 90 & 80 & 96 & 96 \\
\hline $\boldsymbol{x}_{\boldsymbol{j}}^{-}$ & 75 & 70 & 69 & 75 \\
\hline
\end{tabular}

TABLE VI. RESULT

\begin{tabular}{|l|c|c|c|c|}
\hline & $\boldsymbol{S}_{\boldsymbol{i}}$ & $\boldsymbol{R}_{\boldsymbol{i}}$ & $\boldsymbol{Q}_{\boldsymbol{i}}$ & Rank \\
\hline $\boldsymbol{A}_{\mathbf{1}}$ & 0.423997 & 0.294041 & 0.467016 & 2 \\
\hline $\boldsymbol{A}_{\mathbf{2}}$ & 0.274038 & 0.147021 & 0 & 1 \\
\hline $\boldsymbol{A}_{\mathbf{3}}$ & 0.550943 & 0.319506 & 0.713381 & 4 \\
\hline $\boldsymbol{A}_{\mathbf{4}}$ & 0.579133 & 0.479259 & 1 & 5 \\
\hline $\boldsymbol{A}_{\mathbf{5}}$ & 0.535828 & 0.255605 & 0.592444 & 3 \\
\hline
\end{tabular}




\section{SYSTEM SOFTWARE}

The system's software package presented in this paper was developed using the Asp.Net Core technology. One of the most important components of a decision-making system is the database, which contains the data on the basis of which the entire system works. The Entity Relationship (EER) model of the database is presented in Figure 2, and is designed with the visual studio 2017 ado.net entity data model.

The database was implemented on an SQL server. The system's database and business logic have been designed in such a way that it is easy to add new modules to it and improve the system. The system's software, according to the system roles, consists of 4 modules: Administrator Module, Expert Module, Manager Module, and Research Project Submission Module. Some fragments of the system software are given in Figures 3-8. Figure 3 presents the form of the determination of the evaluation criteria according to the scientific directions. Figure 4 presents the form of the determination of the weights of the evaluation criteria. Figure 5 presents the form of the assignment of experts according to the scientific directions. Figure 6 shows the upload page of a scientific project. Figure 7 presents the evaluation form of the scientific projects by the experts, and Figure 8 presents the ranking form of the scientific projects.

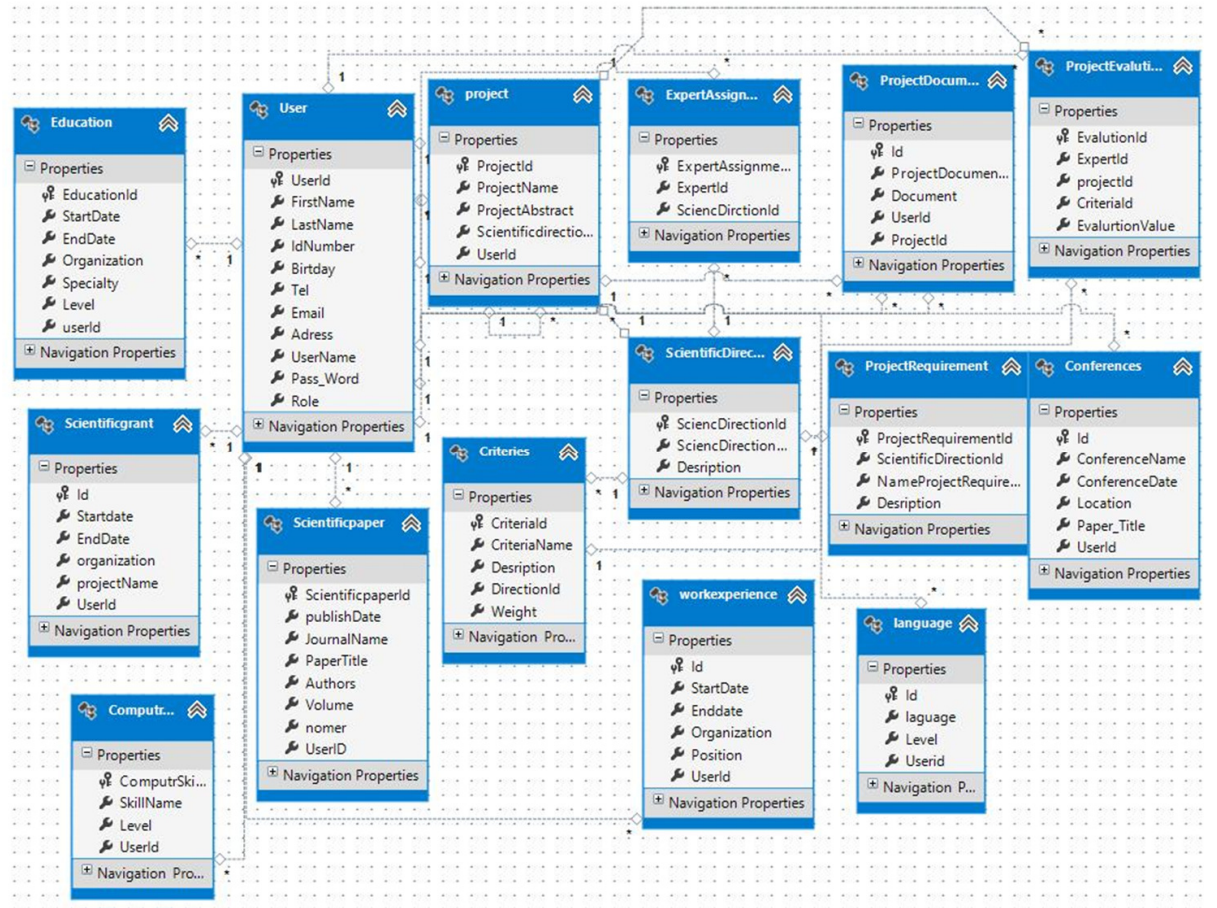

Fig. 2. The EER model of the database.

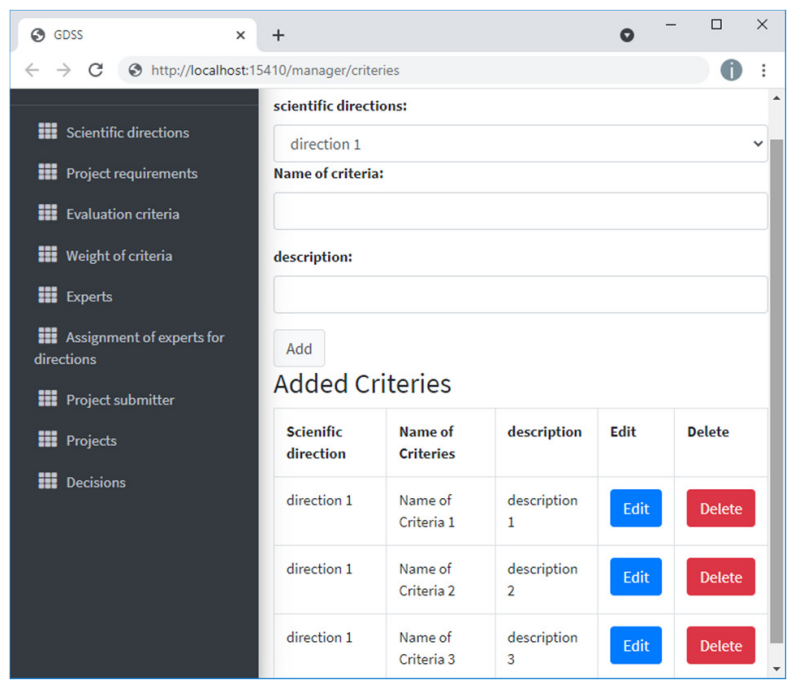

Fig. 3. The evalution criteria.

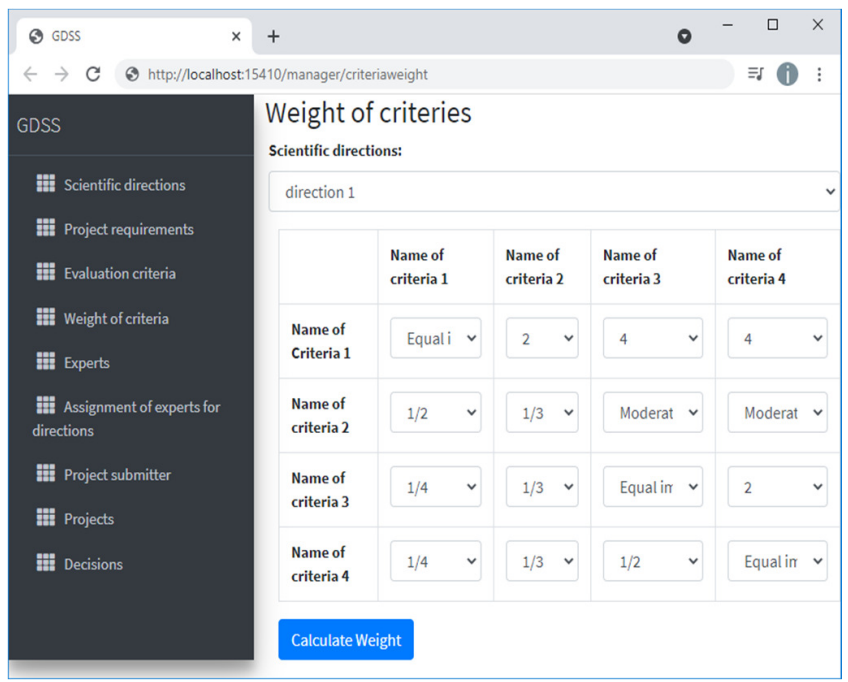

Fig. 4. The weights of the evaluation criteria. 


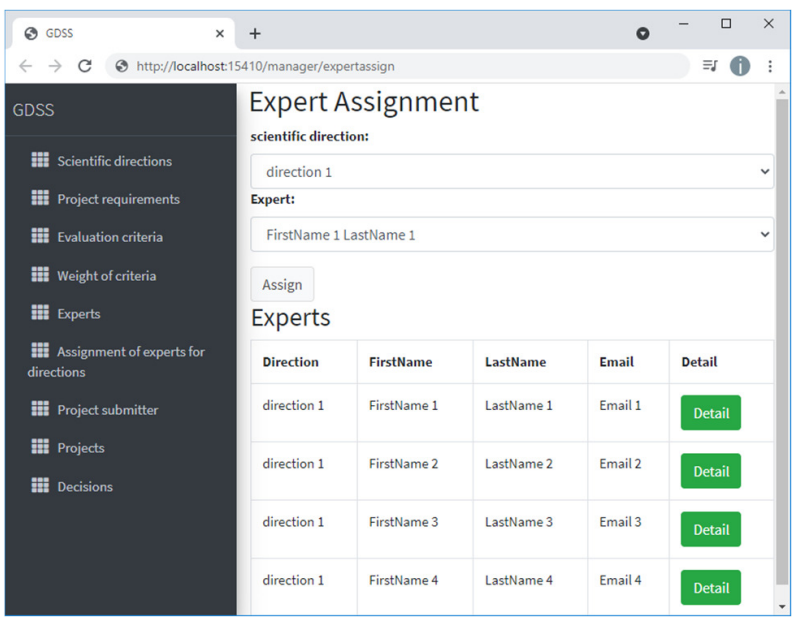

Fig. 5. The assignment of experts.

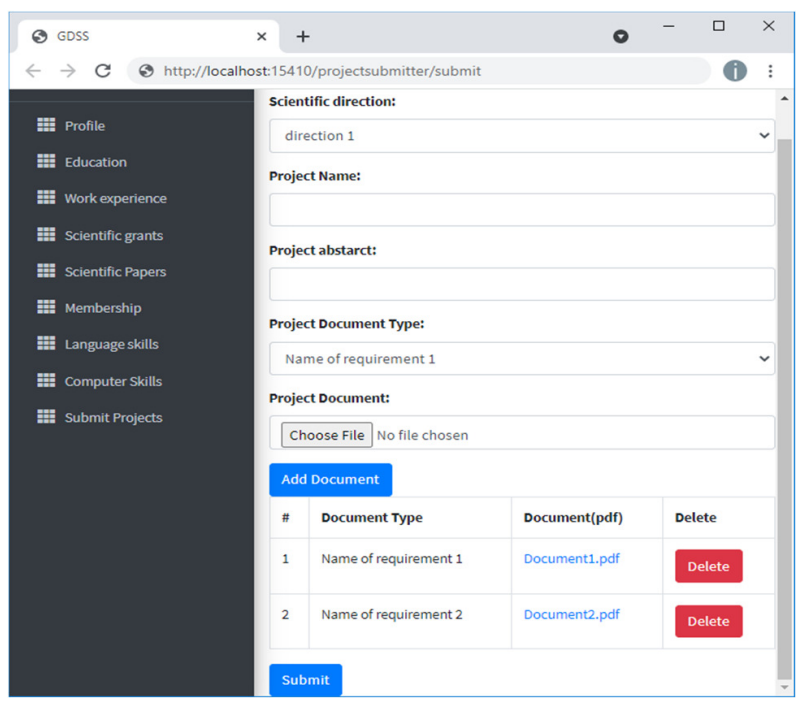

Fig. 6. Project submission.

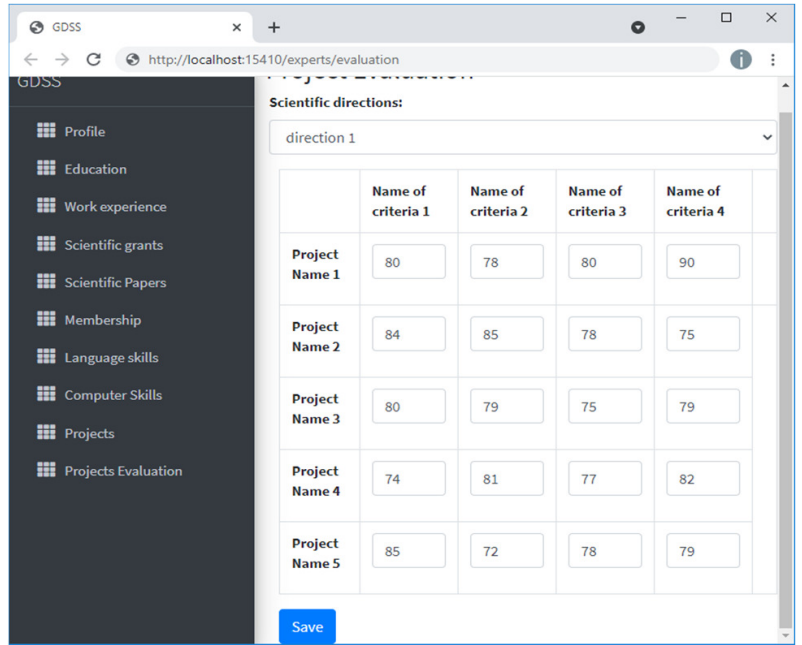

Fig. 7. Evaluation of the scientific projects by the experts.

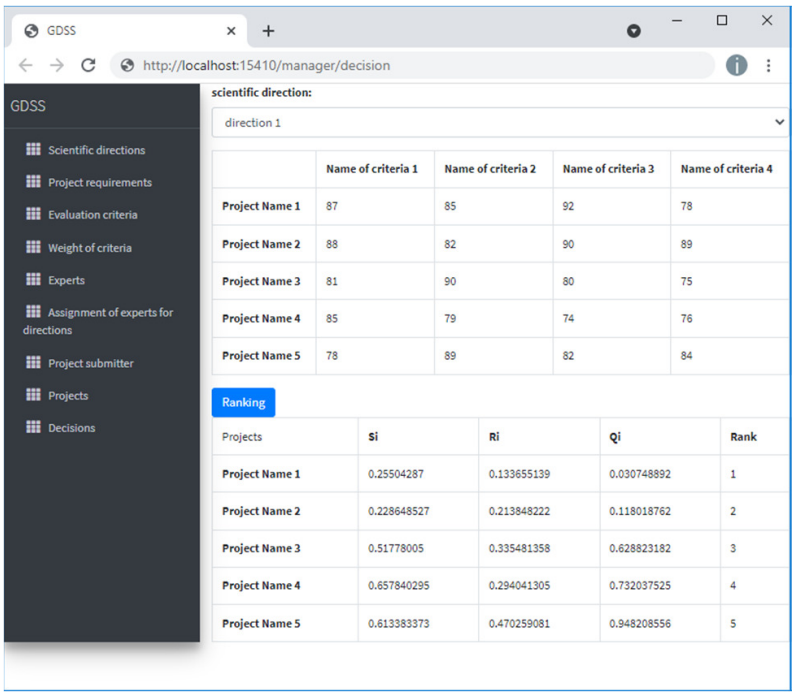

Fig. 8. Ranking of the scientific projects.

\section{CONCLUSION}

The current paper presents a group decision support system for the selection of research projects, which can be effectively used by organizations to conduct research grant competitions fairly and effectively. The resulting system is designed in such a way that it is easy to add new functionalities in order to make it more convenient for a particular organization.

\section{REFERENCES}

[1] C.-L. Hwang and M.-J. Lin, Eds., Group Decision Making under Multiple Criteria. Berlin, Heidelberg, Germany: Springer, 1987.

[2] I. Basheleishvili, "Developing the Expert Decision-Making Algorithm Using the Methods of Multi-Criteria Analysis," Cybernetics and Information Technologies, vol. 20, no. 2, pp. 22-29, Jun. 2020, https://oi.org/10.2478/cait-2020-0013.

[3] C. Zopounidis and P. M. Pardalos, Eds., Handbook of Multicriteria Analysis. Berlin, Heidelberg, Germany: Springer, 2010.

[4] T. L. Saaty and K. Peniwati, Group Decision Making: Drawing Out and Reconciling Differences, 1st ed. Pittsburgh, PA, USA: RWS Publications, 2007.

[5] D. Sabaei, J. Erkoyuncu, and R. Roy, "A Review of Multi-criteria Decision Making Methods for Enhanced Maintenance Delivery," Procedia CIRP, vol. 37, pp. 30-35, Jan. 2015, https://doi.org/10.1016/ j.procir.2015.08.086

[6] T. L. Saaty, "Group Decision Making and the AHP," in The Analytic Hierarchy Process: Applications and Studies, B. L. Golden, E. A. Wasil, and P. T. Harker, Eds. Berlin, Heidelberg, Germany: Springer, 1989, pp. $59-67$.

[7] V. Podvezko, "Application of AHP technique," Journal of Business Economics and Management, vol. 10, no. 2, pp. 181-189, Jun. 2009, https://doi.org/10.3846/1611-1699.2009.10.181-189.

[8] R. Hruška, P. Průša, and D. Babić, "The use of AHP method for selection of supplier," Transport, vol. 29, no. 2, pp. 195-203, Apr. 2014, https://doi.org/10.3846/16484142.2014.930928.

[9] A. Jahan, F. Mustapha, M. Y. Ismail, S. M. Sapuan, and M. Bahraminasab, "A comprehensive VIKOR method for material selection," Materials \& Design, vol. 32, no. 3, pp. 1215-1221, Mar. 2011, https://doi.org/10.1016/j.matdes.2010.10.015.

[10] İ. Basheleishvili, A. Bardavelidze, and S. Tsiramua, "The Development of a Model for Decision Support System of Assessment and Selection of University Academic Staff," Journal of Intelligent Systems: Theory and Applications, vol. 2, no. 2, pp. 18-23, May 2019, https://doi.org/ 10.38016/jista.538991. 
[11] I. Basheleishvili, "Development of Method of Multifunctional Personnel Assessment Using a Topsis Method," Journal of Technical Science and Technologies, vol. 7, no. 1, pp. 31-36, Dec. 2018, https://doi.org/ 10.31578/.v7i1.137.

[12] I. Basheleishvili and A. Bardavelidze, "Designing the Decision-Making Support System for the Assessment and Selection of the University's Academic Staff," International Journal on Information Technologies \& Security, vol. 11, no. 2, pp. 51-58, 2019.

[13] I. Basheleishvili, "The Algorithm of Selection and Functions Distribution of Multifunctional Personnel - Case when the Number of Functions is Greater than the Number of Personnel," Journal of Technical Science \& Technologies, vol. 6, no. 2, pp. 23-26, 2017.

[14] N. Benmoussa, A. Elyamami, K. Mansouri, M. Qbadou, and E. Illoussamen, "A Multi-Criteria Decision Making Approach for Enhancing University Accreditation Process," Engineering, Technology \& Applied Science Research, vol. 9, no. 1, pp. 3726-3733, Feb. 2019, https://doi.org/10.48084/etasr.2352.

[15] Ateekh-Ur-Rehman and M. Alkahtani, "Automobile Tire Assessment: A Multi-Criteria Approach," Engineering, Technology \& Applied Science Research, vol. 7, no. 1, pp. 1363-1368, Feb. 2017, https://doi.org/ 10.48084/etasr.797.

[16] S. Alshehri, "Multicriteria Decision Making (MCDM) Methods for Ranking Estimation Techniques in Extreme Programming," Engineering, Technology \& Applied Science Research, vol. 8, no. 3, pp. 3073-3078, Jun. 2018, https://doi.org/10.48084/etasr.2104. 